\title{
Aicardi-Goutières syndrome
}

INSERM

\section{Source}

INSERM. (1999). Orphanet: an online rare disease and orphan drug data base. AicardiGoutières syndrome. ORPHA:51

Aicardi-Goutières syndrome (AGS) is an inherited, subacute encephalopathy characterised by the association of basal gang lia calcification, leukodystrophy and cerebrospinal fluid (CSF) lymphocytosis. 